\title{
EXPERIMENTAL INVESTIGATION ON ROLING-SLIDING Contact Properties OF WC CERMET COATINGS
}

\author{
D. M. Nuruzzaman ${ }^{1}$, A. Nakajima ${ }^{2}$ and T. Mawatari ${ }^{3}$ \\ ${ }^{1}$ Department of Mechanical Engineering \\ Dhaka University of Engineering and Technology, Gazipur-1700, Bangladesh. \\ ${ }^{2,3}$ Department of Mechanical Engineering \\ Saga University, 1, Honjo-machi, Saga-shi, Saga 840-8502, Japan. \\ E-mail: dewan052005@yahoo.com
}

\begin{abstract}
In this study, tribological properties of $\mathrm{Hi}-\mathrm{HVOF}$ sprayed WC-Cr-Ni cermet coatings were investigated experimentally under lubricated rolling-sliding contact. Coatings were deposited onto the induction hardened carbon steel and carburized hardened steel materials. Substrate surfaces were prepared by axially grinding, blasting and circumferentially grinding. Under the operating conditions of contact pressure $P_{H}=1.4 \mathrm{GPa}$ and slip ratio $s=-28.0 \%$, the effects of substrate hardness and substrate surface kind on the tribological properties of the cermet coating were examined. It was found that cermet coating showed a long life and durability was not influenced by the substrate hardness and substrate surface kind. It was also found that during the running-in process, oil film formation was hardly influenced by the substrate hardness and substrate surface kind. On the other hand, surface hardness and surface roughness of the coating were more influenced in the case of circumferentially ground substrate than that in the case of axially ground or blasted substrate. In addition, coating material loss was very high in the case of circumferentially ground substrate when the substrate material was induction hardened carbon steel.
\end{abstract}

Keywords: Tribological Properties, WC-Cr-Ni Cermet, Substrate Hardness, Substrate Surface Kind

\section{Introduction}

A number of coating deposition techniques are available for the modification of surface characteristics in order to improve the tribological performance of machine elements. In recent years, the quality and reliability of thermally sprayed coatings have been improved remarkably to satisfy the growing needs of the market for high wear resistance of engineering components. This is due to the development of new processes so that the coating deposition system can be designed to optimize the velocity and temperature of the spray particles or due to the introduction of advanced techniques such as application of heat sources with higher energy and controlling the spray parameters [1-3]. Among the cermet coatings, the most attractive proved to be the hard coatings of tungsten carbide (WC) based cermets because of its excellent tribological properties [4]. These cermet coatings can be prepared by the conventional type high velocity oxy-fuel flame spraying (HVOF) and the high energy type flame spraying (Hi-HVOF) processes. The resulting coatings are durable in wear applications due to their high hardness and low porosity. The investigations on the tribological properties of these thermally sprayed cermet coatings under rolling-sliding contact conditions are described in a number of published literature [5-9]. Results showed that tribological properties of these coatings are significantly influenced by a number of parameters such as contact pressure, coating thickness, mating surface roughness, substrate material, spraying process, slip ratio etc.

The influence of spray parameters on the particle in-flight properties and coating properties during HVOF spraying of WC cermet powder was investigated [10]. It was found that the spray parameters such as the total gas flow rate, the powder feed rate and the spray distance influenced the particle properties and the coating properties to different degrees. Durability of WC cermet coating was investigated under lubricated rolling-sliding contact [11]. It was found that durability was significantly influenced by the substrate surface finish. Surface durability of WC cermet coated steel roller was examined under rolling-sliding contact and it was found that durability of the coating was greatly influenced by the substrate material [12].

In this study, tribological properties of ther- 
mally sprayed WC-Cr-Ni cermet coating were investigated experimentally under lubricated rolling-sliding contact. Coatings were deposited onto the axially ground, blasted and circumferentially ground roller specimens made of an induction hardened carbon steel or a carburized hardened steel. Under a contact pressure $\mathrm{P}_{\mathrm{H}}=1.4 \mathrm{GPa}$ and slip ratio $s=-28.0 \%$, the effects of substrate hardness and substrate surface kind on the durability of cermet coating were investigated. The effects of substrate hardness and substrate surface kind on oil film formation, surface hardness, surface roughness and coating material loss were also examined.

\section{Experimental Details}

2.1 Test Specimen (coated roller) and Mating Non-coated Roller

The substrate material of the test specimen is an induction hardened carbon steel or a carburized hardened steel and the coating material is WC-Cr-Ni cermet. Chemical compositions of the substrate material and the coating material are shown in Table 1. The material of the mating non-coated roller is a carburized and hardened chromium molybdenum steel and its composition is same as the substrate material shown in Table 1.

\subsection{Substrate Surface Preparation and} Thermal Spraying Conditions

Before applying the thermally sprayed coating onto the induction hardened carbon steel substrate or carburized hardened steel substrate, the substrate surface was prepared so that coating material can adhere with the substrate material. Three types of substrate surfaces were prepared by axially grinding, shot-blasting and circumferential grinding. After surface preparation, the maximum surface roughness was $\mathrm{R}_{\max }=7.0 \mu \mathrm{m}$. After that, WC-Cr-Ni cermet coating was formed onto the axially ground, blasted and circumferentially ground roller specimens by means of the high energy type flame spraying (Hi-HVOF) and the spraying conditions are shown in Table 2.

\subsection{Specifications of Rollers}

WC-Cr-Ni cermet coating of about $60 \mu \mathrm{m}$ in thickness was prepared. After spraying, the contact surface of coated roller was finished smooth to a mirror-like condition with a maximum surface roughness $\mathrm{R}_{\max }=0.2 \mu \mathrm{m}$ by grinding and subsequent polishing. The micro-Vickers hardness of the coating formed by Hi-HVOF was $\mathrm{HV} \approx 1080$ (test load: 2.94 Newton). The maximum surface roughness of non-coated roller was $\mathrm{R}_{\max }=5 \sim 6 \mu \mathrm{m}$. The detail specifications of coated roller and mating non-coated roller are shown in Table 3.

2.4 Testing Machine, Test Conditions and Lubricating Oil

Using a two-roller testing machine shown in Fig. 1, experiments were carried out to investigate the tribological properties of thermally sprayed WC-Cr-Ni cermet coating under lubricated rolling-sliding contact conditions. In the experiments, using a coil spring the normal load was applied in line contact condition. The normal load which gives the Hertzian contact pressure $\mathrm{P}_{\mathrm{H}}=1.4 \mathrm{GPa}$ was applied. Moreover, under rolling with sliding contact condition, using the gear ratio 25/32, a slip ratio $\mathrm{s}=-28.0 \%$ was applied. An automatic stopping device was attached with the testing machine and this device worked in response to any abnormal vibration induced by the occurrence of flaking/delamination of coating. In the experiments, durability or life to flaking of coating $\mathrm{N}$ is defined as the total number of revolutions of the coated roller. When the testing machine continued to run without any flaking of the coating, the running was discontinued at $\mathrm{N}=2.0 \times 10^{7}$ cycles. As lubricant, a paraffinic mineral oil without extreme pressure (EP) additives (kinematic viscosity v: $62.9 \mathrm{~mm}^{2} / \mathrm{s}$ at $313 \mathrm{~K}, 8.5 \mathrm{~mm}^{2} / \mathrm{s}$ at $373 \mathrm{~K}$, pressure-viscosity coefficient $\alpha$ : $13.3 \mathrm{GPa}^{-1}$ at $313 \mathrm{~K}$ ) was supplied at a flow rate of $15 \mathrm{~cm}^{3} / \mathrm{s}$ and at a constant oil temperature of $318 \mathrm{~K}$. The state of oil film formation with the number of cycles was measured by means of an electrical contact resistance method [13].

\section{Results and Discussion}

Fig. 2 exhibits the effects of substrate hardness and substrate surface kind on durability or life to flaking of WC cermet coating under the operating conditions of contact pressure $\mathrm{PH}=1.4 \mathrm{GPa}$ and slip ratio $\mathrm{s}=-28.0 \%$. From the figure it can be seen that in the case of induction hardened carbon steel substrate $(\mathrm{HV}=680)$, the coating on the axially ground substrate showed a high durability and it showed a long life over $\mathrm{N}=2.0 \times 107$ cycles. It can also be observed that in the case of blasted or circumferentially ground substrate, coating showed a long life and it was possi- 
ble to run over $\mathrm{N}=2.0 \times 107$ cycles. In the case of carburized hardened steel substrate $(\mathrm{HV}=770)$, the coating also exhibited a high durability and it showed a long life over
$\mathrm{N}=2.0 \times 107$ cycles when the substrate surface was axially ground, blasted or circumferentially ground.

Table 1 Chemical composition (by mass\%) of test specimen (coated roller)

\begin{tabular}{|c|c|c|c|c|c|c|c|c|c|}
\hline $\begin{array}{c}\text { Induction hardened } \\
\text { carbon steel (sub- } \\
\text { strate) }\end{array}$ & $\mathrm{Fe}$ & $\mathrm{C}$ & $\mathrm{Si}$ & $\mathrm{Mn}$ & $\mathrm{P}$ & $\mathrm{S}$ & $\mathrm{Cu}$ & $\mathrm{Ni}$ & $\mathrm{Cr}$ \\
\cline { 2 - 10 } & Balance & 0.44 & 0.19 & 0.75 & 0.01 & 0.03 & 0.16 & 0.50 & 0.14 \\
\hline $\begin{array}{c}\text { Carburized hardened } \\
\text { steel (substrate) }\end{array}$ & $\mathrm{Fe}$ & $\mathrm{C}$ & $\mathrm{Si}$ & $\mathrm{Mn}$ & $\mathrm{P}$ & $\mathrm{S}$ & $\mathrm{Cu}$ & $\mathrm{Mo}$ & $\mathrm{Cr}$ \\
\cline { 2 - 10 } & Balance & 0.18 & 0.30 & 0.90 & 0.01 & 0.03 & 0.10 & 0.35 & 1.25 \\
\hline $\begin{array}{c}\text { Thermally sprayed } \\
\text { coating }\end{array}$ & \multicolumn{3}{|c|}{$\mathrm{WC}$} & \multicolumn{3}{c|}{$\mathrm{Cr}$} & \multicolumn{3}{c|}{$\mathrm{Ni}$} \\
\cline { 2 - 10 } & \multicolumn{3}{c|}{ Balance } & \multicolumn{3}{c}{7} \\
\hline
\end{tabular}

Table 2 Spraying conditions

\begin{tabular}{|c|c|c|}
\hline \multicolumn{2}{|c|}{ Spraying process } & \multirow{2}{*}{$\begin{array}{c}\text { Hi-HVOF } \\
1.0\end{array}$} \\
\hline Pressure $\mathrm{MPa}$ & Oxygen & \\
\hline Hessute, 1710 a & Fuel* & 0.9 \\
\hline \multirow{2}{*}{ Flow rate, $\mathrm{m}^{3} / \mathrm{h}$} & Oxygen & 53.6 \\
\hline & Fuel* & 0.02 \\
\hline \multicolumn{2}{|c|}{ Sprayed distance, $\mathrm{mm}$} & 380 \\
\hline \multicolumn{2}{|c|}{ Velocity of coating particles, $\mathrm{m} / \mathrm{s}$} & 1080 \\
\hline \multicolumn{2}{|c|}{ Velocity of gas, $\mathrm{m} / \mathrm{s}$} & 2160 \\
\hline
\end{tabular}

* Fuel: Kerosene

Table 3 Specifications of coated and non-coated rollers

\begin{tabular}{|l|c|}
\hline Diameter of coated and non-coated rollers, mm & 60 \\
\hline Micro-Vickers hardness of coating (Hi-HVOF), HV & 1080 \\
\hline Micro-Vickers hardness of substrate (Induction hardened), HV & 680 \\
\hline Micro-Vickers hardness of substrate (Carburized hardened), HV & 770 \\
\hline Micro-Vickers hardness of non-coated roller, HV & 780 \\
\hline Maximum surface roughness of the substrate, $\mu \mathrm{m}$ & 7.0 \\
\hline Maximum surface roughness of coated roller, $\mu \mathrm{m}$ & 0.2 \\
\hline Maximum surface roughness of non-coated roller, $\mu \mathrm{m}$ & $5 \sim 6$ \\
\hline Effective track width in line contact condition, mm & 10 \\
\hline Coating thickness, $\mu \mathrm{m}$ & 60 \\
\hline
\end{tabular}

Fig. 3 shows the effect of substrate surface kind on change in the electrical contact voltage with the number of cycles under the operating conditions of contact pressure $\mathrm{P}_{\mathrm{H}}=1.4$ $\mathrm{GPa}$ and slip ratio $\mathrm{s}=-28.0 \%$. In this case, the substrate material was induction hardened carbon steel. These results were the measurements of the state of oil film formation using the electrical contact resistance method and the results are shown up to $\mathrm{N}=6.0 \times 10^{4}$ cycles. During running-in, the variations of average electrical contact voltage which corresponds to the changes in the electrical contact resistance arising from the formation or breakdown 


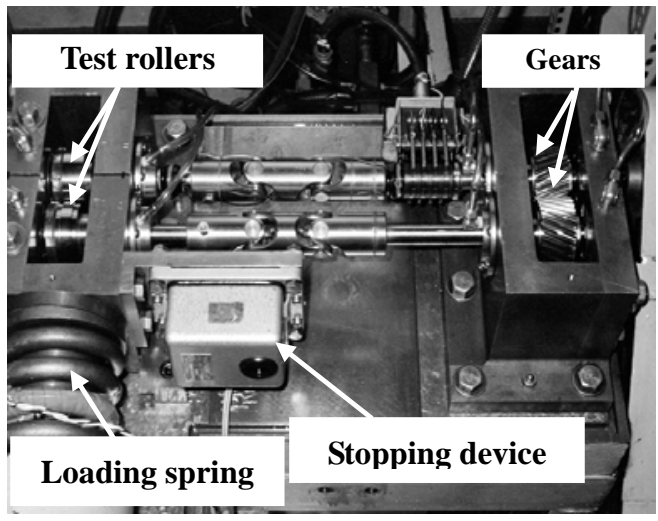

Fig. 1 Two-roller testing machine

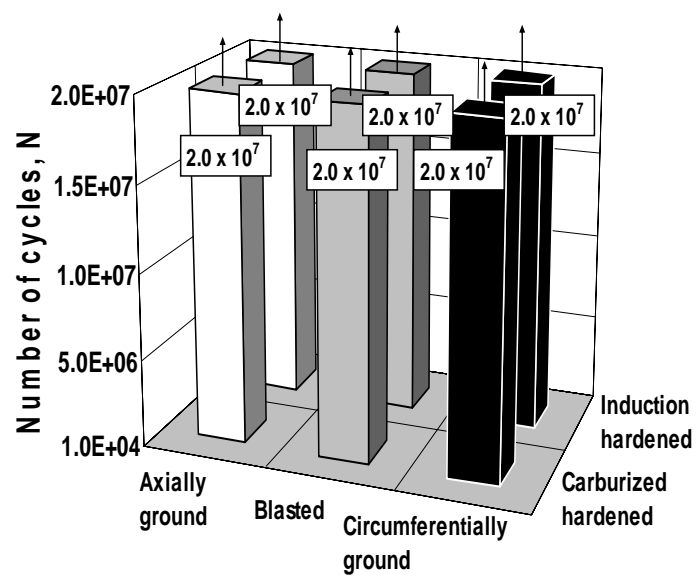

Fig. 2 Effects of substrate hardness and substrate surface kind on durability or life to flaking of WC cermet coating

of oil film were plotted. In the measurements, contact voltage $=0 \mathrm{mV}$ means metal-to-metal contact, while contact voltage $=15 \mathrm{mV}$ means complete separation of the surfaces by oil film. As is apparent from the figure and in the case of axially ground substrate, at the very early stage of running, the separation voltage was very near to zero or extremely low value and it increased steadily with the number of cycles. From the figure it can also be observed that formation of oil film followed almost the same trend when the substrate surface was blasted or circumferentially ground. From the obtained results it could be considered that oil film formation was hardly influenced by the substrate surface kind. However, there was a very little difference in the state of oil film formation during running-in depending on the running conditions. Fig. 4 also shows the effect of substrate surface kind on change in the electrical contact voltage but in this case, the substrate material was carburized hardened steel. From the figure it is apparent that formation of oil film followed very similar trend to that for the lower hardness substrate material (Fig. 3). Moreover, it is very clear that oil film formation was not influenced by the substrate surface kind.

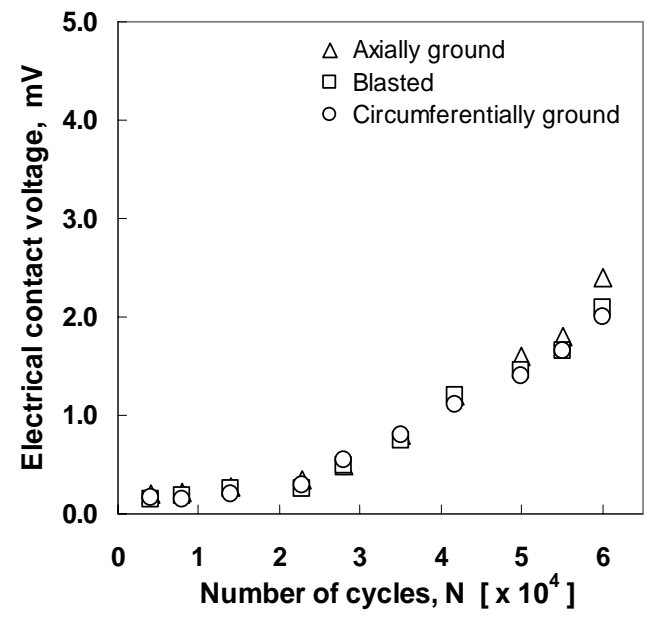

Fig. 3 Effect of substrate surface kind on change in the electrical contact voltage (Induction hardened)

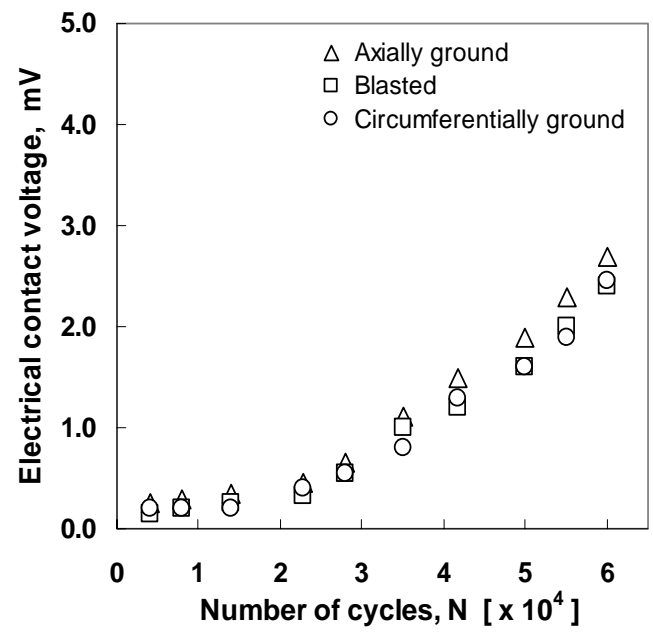

Fig. 4 Effect of substrate surface kind on change in the electrical contact voltage (Carburized hardened)

Fig. 5 illustrates the effect of substrate surface kind on surface hardness of the WC-Cr-Ni cermet coating in the case of induction hardened carbon steel substrate. From the figure it can be observed that before the test, hardness of coated surface was about 
$1080 \mathrm{HV}$ and after the test, surface hardness was much increased. Namely, in the case of axially ground substrate, after the test, hardness of the coated surface became about 1220 $\mathrm{HV}$ and in the case of blasted substrate, after the test, hardness of the coated surface became about $1260 \mathrm{HV}$. On the other hand, in the case of circumferentially ground substrate, after the test, hardness of the coated surface was significantly increased and it became about $1330 \mathrm{HV}$. From these results it is apparent that during the running-in process, work hardening of the coated surface occurred and surface hardness of the coating was much more influenced in the case of circumferentially ground substrate than that in the case of axially ground or blasted substrate. Fig. 6 exhibits the effect of substrate surface kind on surface hardness of coating in the case of carburized hardened steel substrate. From the figure it can be seen that in the case of axially ground substrate, after experiment the surface hardness became about $1190 \mathrm{HV}$ and in the case of blasted substrate, the surface hardness became about 1200 HV. But in the case of circumferentially ground substrate, the surface hardness was much increased and it became about 1270 HV. From the obtained results, it is concluded that substrate surface kind is an influential factor for increased surface hardness of the coating. Moreover, when these results are compared with the results of Fig. 5, it is concluded that surface hardness was more influenced by the substrate surface kind when the substrate material was induction hardened steel than that of carburized hardened steel substrate.

Fig. 7 shows the effect of substrate surface kind on surface roughness of WC cermet coated roller. In the experiments, the coated induction hardened steel roller was mated with the non-coated carburized hardened steel roller. From the figure it can be seen that in the case of axially ground substrate, before experiment, the surface roughness of coated roller was about $0.2 \mu \mathrm{m}$ and after experiment, the surface roughness was much increased and it became about $1.5 \mu \mathrm{m}$. In the case of blasted substrate, after experiment, the surface roughness of the coated roller was greatly increased and it became about 2.0 $\mu \mathrm{m}$.

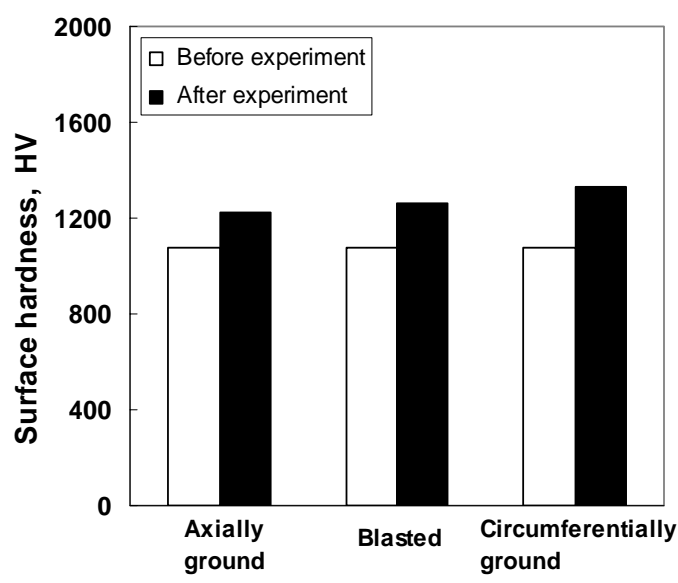

Fig. 5 Effect of substrate surface kind on surface hardness (Induction hardened)

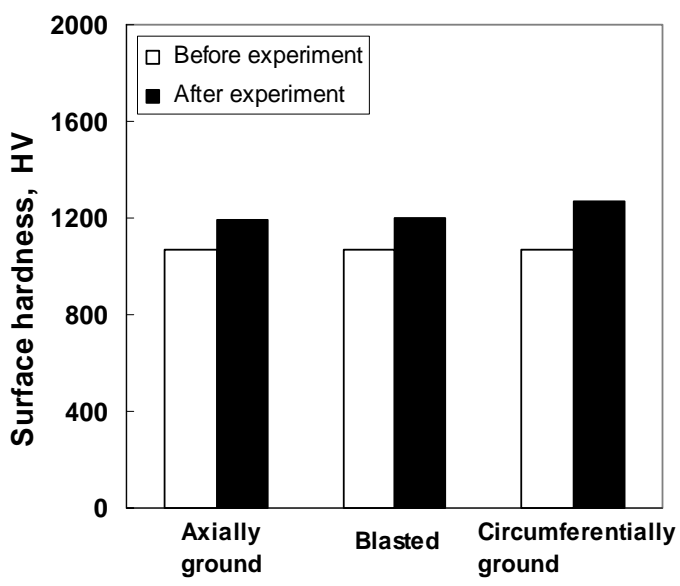

Fig. 6 Effect of substrate surface kind on surface hardness (Carburized hardened)

In the case of circumferentially ground substrate, before experiment, the surface roughness of coated roller was about $0.2 \mu \mathrm{m}$ whereas after experiment, the surface roughness of coated roller was significantly increased and it became about $3.0 \mu \mathrm{m}$. The obtained results revealed that after running, roughness of the coated surface was much more influenced in the case of circumferentially ground substrate than that in the case of axially ground or blasted substrate. Fig. 8 also shows the effect of substrate surface kind on surface roughness of the coated roller. In this case, the coated carburized hardened steel roller was mated with the non-coated carburized hardened steel roller. From the figure it can be seen that after experiment, surface roughness of the coating became about $2.0,3.0$ and $4.0 \mu \mathrm{m}$ in case of axially 
ground, blasted and circumferentially ground substrate surface respectively. When these results are compared with the results of Fig. 7, it can be concluded that surface roughness of the coating was much influenced by the substrate surface kind but hardly influenced by the substrate hardness.

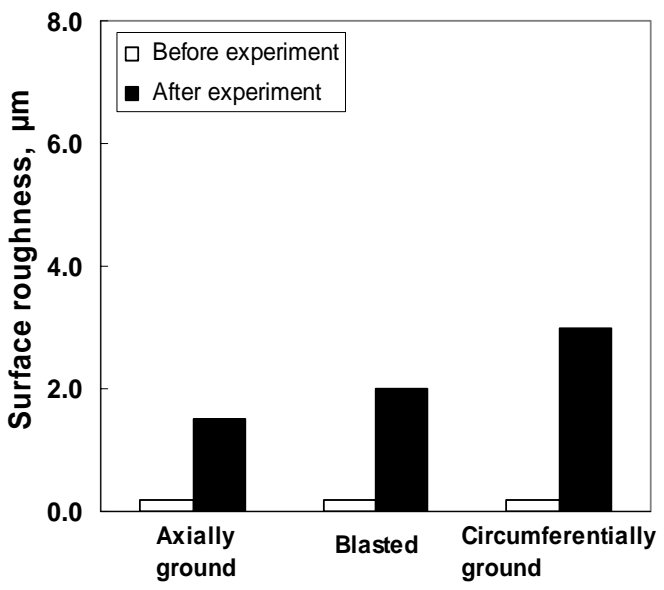

Fig. 7 Effect of substrate surface kind on surface roughness (Induction hardened)

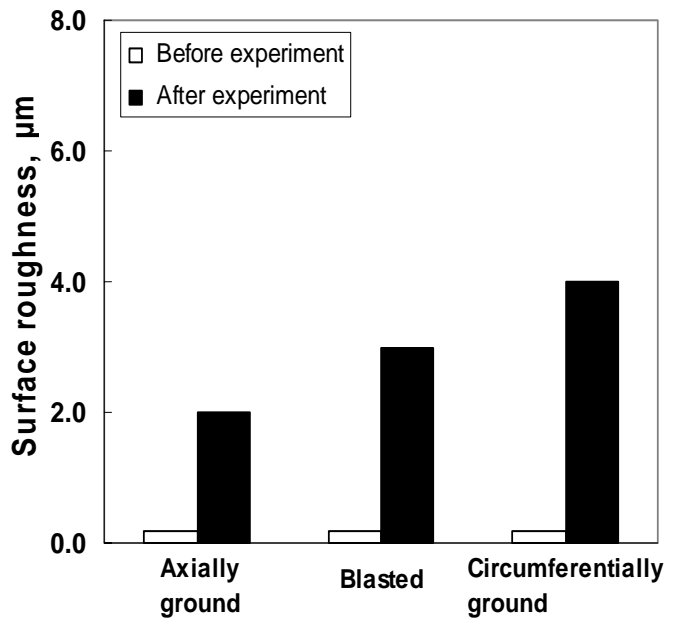

Fig. 8 Effect of substrate surface kind on surface roughness (Carburized hardened)

Fig. 9 shows the effect of substrate surface kind on material loss of WC cermet coating. In the experiments, the coated induction hardened steel roller was mated with the non-coated carburized hardened steel roller. In the case of axially ground substrate, it can be seen that after the running-in process, the coating material loss was $10 \mathrm{mg}$. It can also be observed that in the case of blasted substrate, the coating material loss was same as $10 \mathrm{mg}$. On the other hand, in the case of circumferentially ground substrate, the coating material loss was remarkably increased to $90 \mathrm{mg}$. From these results it is apparent that the loss of coating material was significantly higher in the case of circumferentially ground substrate than that in the case of axially ground or blasted substrate. Fig. 10 demonstrates the effect of substrate surface kind on coating material loss in the case of carburized hardened steel substrate roller. It can be observed that in the case of axially ground, blasted and circumferentially ground substrate surface, the coating material loss was 9 , 10 and $28 \mathrm{mg}$ respectively. From these results it can be concluded that in general, the coating material loss was higher in the case of circumferentially ground substrate than that in the case of axially ground or blasted substrate.

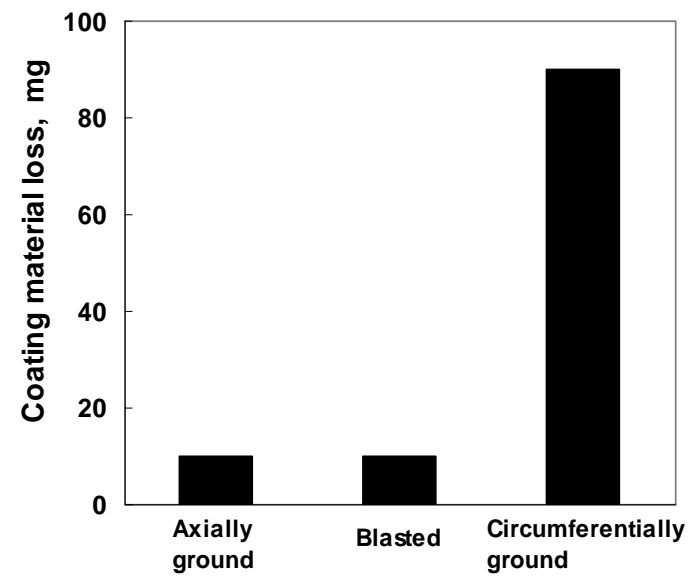

Fig. 9 Effect of substrate surface kind on coating material loss (Induction hardened)

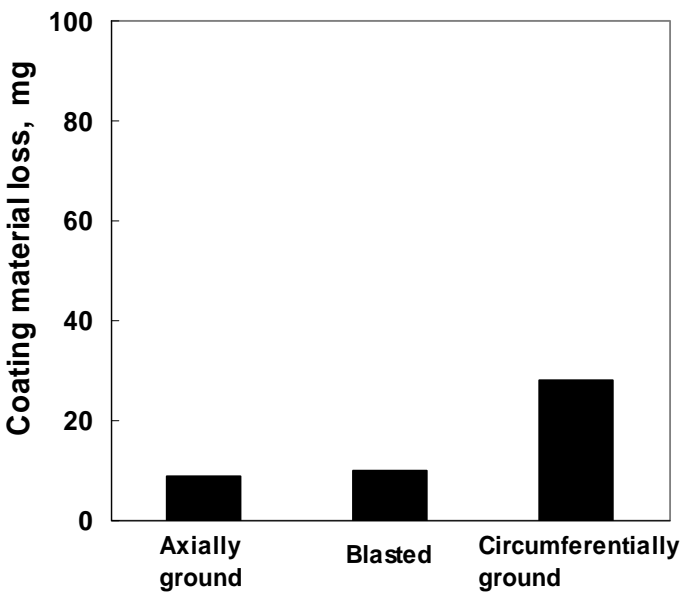

Fig. 10 Effect of substrate surface kind on coating material loss (Carburized hardened) 


\section{Conclusions}

Properties of Hi-HVOF sprayed WC-Cr-Ni cermet coating were investigated experimentally under lubricated rolling-sliding contact. The substrate material was an induction hardened carbon steel or a carburized hardened steel. The effects of substrate surface kind and substrate hardness on the properties of cermet coating were examined. From the obtained results it can be concluded that cermet coating showed a high durability and it was found that life of the coating was not influenced by the substrate surface kind and substrate hardness. In addition, oil film formation was hardly influenced by the substrate surface kind and substrate hardness. After the running-in process, in general, surface hardness of the coating was much more increased in the case of circumferentially ground substrate than that in the case of axially ground or blasted substrate. Moreover, surface hardness of the coating was more influenced in the case of induction hardened steel substrate than that in the case of carburized hardened steel substrate. Roughness of the coated surface was much more influenced in the case of circumferentially ground substrate than that in the case of axially ground or blasted substrate. It was also found that surface roughness was hardly influenced by the substrate hardness. Generally, the loss of coating material was higher in the case of circumferentially ground substrate than that in the case of axially ground or blasted substrate but the coating material loss was very high for the lower hardness substrate material.

\section{References}

[1] Bhushan, B., Principles and Applications of Tribology, John Wiley \& Sons, Inc., New York, 1999.

[2] Harada, Y., "Recent development of thermal spraying technology and it's applications", Bulletin, Japan Institute of Metals, Vol. 31, 1992, pp.
413-421.

[3] Budinski, K.G., Surface Engineering for Wear Resistance, Prentice Hall, Englewood Cliffs, New Jersey, 1988.

[4] Knapp, J. K. and Nitta, H., "Fine-Particle Slurry Wear Resistance of Selected Tungsten Carbide Thermal Spray Coatings", Tribology International, Vol. 30, 1997,pp. 225-234.

[5] Tani, K., Nakahira, H., Miyajima, K. and Harada, Y., "Thermal and Elastic Anisotropy of Thermally Sprayed Coatings", Material Transaction JIM, Vol. 33, 1992, pp. 618-626.

[6] Ahmed, R. and Hadfield, M., "Wear of High Velocity Oxy-fuel(HVOF)-Coated Cones in Rolling Contact", Wear, Vol. 203-204, 1997, pp. 98-106.

[7] Ahmed, R. and Hadfield, M., "Rolling Contact Fatigue Performance of Detonation Gun Coated Elements", Tribology International, Vol. 30, 1997, pp. 129-137.

[8] Ahmed, R. and Hadfield, M., "Rolling Contact Fatigue Behavior of Thermally Sprayed Rolling Elements", Surface and Coatings Technology, Vol. 82, 1996, pp. 176-186.

[9] Nakajima, A., Mawatari, T., Yoshida, M., Tani, K. and Nakahira, A., "Effects of Coating Thickness and Slip Ratio on Durability of Thermally Sprayed WC Cermet Coating in Rolling/Sliding Contact", Wear, Vol. 241, 2000, pp. 166-173.

[10] Zhao, L., Maurer, M., Fischer, F., Dicks, R. and Lugscheider, E., "Influence of Spray Parameters on the Particle In-flight Properties and the Properties of HVOF Coating of WC-CoCr", Wear, Vol. 257, 2004, pp. 41-46.

[11] Nakajima, A., Nuruzzaman, D. M., Mawatari, T. and Yoshida, M., "Effect of Substrate Surface Finish on Durability of Thermally Sprayed WC Cermet Coating under Rolling/Sliding Contact", Japanese Journal of Tribology, Vol. 50, 2005, pp. 437-448.

[12] Nuruzzaman, D. M., Nakajima, A. and Mawatari, T., "Effects of Substrate Surface Finish and Substrate Material on Durability of Thermally Sprayed WC Cermet Coating in Rolling with Sliding Contact", Tribology International, Vol. 39, 2006, pp. 678-685.

[13] Ichimaru, K., Nakajima, A. and Hirano, F., "Effect of Asperity Interaction on Pitting in Rollers and Gears," ASME Journal of Mechanical Design, Vol. 103, 1981, pp. 482-491. 